\title{
PERAN KEPALA SEKOLAH DALAM MENINGKATKAN PROFESIONALITAS GURU DI SEKOLAH MENENGAH PERTAMA NEGERI 1 HALONGONAN TIMUR KABUPATEN PADANG LAWAS UTARA
}

\author{
Syamsu Nahar \\ Email: syamsunahar.edu@gmail.com \\ Pascasarjana UIN Sumatera Utara \\ Edi Saputra \\ Email: edisaputra2009@gmail.com \\ Pascasarjana UIN Sumatera Utara \\ Khairul Anwar \\ Email: khairulanwarsmpn2@gmail.com \\ Mahasiswa Program Studi Pendidikan Islam \\ Pascasarjana UIN Sumatera Utara
}

\begin{abstract}
Abstrak: Penelitian ini bertujuan untuk menganalisis: 1) Bagaimana perencanaan kepala sekolah dalam mengembangkan profesionalitas guru di SMP Negeri 1 Halongonan Timur Kabupaten Padang Lawas Utara, 2) Bagaimana pelaksanaan supervise kepala sekolah dalam mengembangkan profesionalitas guru di SMP Negeri 1 Halongonan Timur Kabupaten Padang Lawas Utara, 3) Bagaimana tindakan kepala sekolah dalam memotivasi guru di SMP Negeri 1 Halongonan Timur Kabupaten Padang Lawas Utara. Penelitian menggunakan pendekatan kualitatif. Teknik pengumpulan data penelitian berupa observasi, wawancara dan dokumentasi. Hasil penelitian ini adalah perencanaan yang dilakukan kepala sekolah adalah membuat kreteria penerimaan anggota baru, membuat program kerja guru per triwulan, menghemat dana sekolah. Pengawasan yang dilakukan adalah pengawasan model formatif dan sumatif yaitu secara berkala dalam setiap minggu masuk langsung ke dalam kelas memperhatikan cara guru mengajar. Motivasi ekstrinsik atau motivasi yang dilakukan oleh kepala sekolah dalam memotivasi gurunya yaitu dengan cara memberikan pujian, selalu bersikap menghormati guru, mendengarkan keluhan guru dan menindaklanjuti apa yang menjadi keluhan guru serta pelatihan di bidang IT. Sedangkan motivasi interinsik yaitu pada saat ada pelatihan guru tidak dapat hadir mengikuti pelatihan tersebut tetapi karena guru tersebut ingin memperoleh ilmu, maka guru itu belajar kepada rekannya agar guru tersebut dapat terus meningkatkan kemampunya.
\end{abstract}

Kata Kunci: Peran dan Profesionalitas 
Edu Riligia : Vol. 4 No. 1 Januari- Maret 2020

\section{Pendahuluan}

Pengawas mempunyai tugas membina, menilai dan meningkatkan kualitas proses dan hasil pendidikan yang dilakukan di sekolah. Dalam menjalankan tugas kepengawasan bukan hanya guru yang menjadi obyek pengawas sekolah tetapi juga kepala sekolah. Demi meningkatkan kualitas manajerial dilakukan supervisi manajerial, sedangkan untuk guru dilakukan supervisi akademik. Tugas utama pengawas adalah melakukan pembinaan dan pengawasan memastikan tercapainya tujuan pendidikan. Oleh karena itu diperlukan perencanaan yang matang serta evaluasi secara terus-menerus oleh pengawas terhadap guru. Beberapa kemampuan yang menunjang tugas pengawas adalah kemampuan untuk mengidentifikasi, merencanakan, mengobservasi dan menilai standar pendidikan nasional yang telah ditetapkan. Berdasarkan tugas dan tanggung jawab tersebut, pengawas juga merupakan mata rantai kunci dalam manajemen yang melakukan kontrol dan monitor terhadap program-program dan kebijakan yang telah ditetapkan oleh pemerintah.

Secara kuantitas, mutu sekolah memperlihatkan kelemahan di bidang jumlah tenaga kependidikan dan kondisi sarana-prasarana. Status guru yang mengajar ada sebagian yang honorer dan memiliki penghasilan yang belum memadai. Dalam pandangan masyarakat juga berkembang image yang tidak baik tentang sekolah, misalnya sebagai sekolah pilihan kedua, kondisi fisiknya yang tidak bersih sampai dengan rendahnya mutu pendidikan yang melekat pada sekolah itu sendiri. Keberhasilan sekolah secara kualitas akan lebih banyak tergantung pada peran pengawas sekolah, guru dan penyelenggara sekolah itu sendiri. Karena bagaimanapun megahnya bangunan sekolah, canggihnya peralatan penunjang pembelajaran yang tersedia, jika guru atau tenaga pengajarnya tidak memiliki profesionalitas yang baik, maka risiko kegagalan pun sangat tinggi. Salah satu tenaga kependidikan yang dinilai strategis dan penting untuk meningkatkan kinerja guru sekolah dan pihak manajemen sekolah adalah tenaga pengawas sekolah.

Menurut pengamatan dan berdasarkan paradigma penulis sekilas di lapangan pengawas sekolah selama ini cenderung lebih banyak melaksanakan supervisi manajerial daripada supervisi akademik. Supervisi akademik, seperti berkunjung ke kelas-kelas mengamati guru yang sedang mengajar tanpa mengganggu, membimbing penyusunan silabus dan RPP, pemilihan strategi/ metode/ teknik pembelajaran, penggunaan media dan teknologi informasi dalam 
Syamsu Nahar: Peran Kepala Sekolah dalam Meningkatkan Profesionalitas Guru

pembelajaran, menilai proses dan hasil pembelajaran serta penelitian tindakan kelas dan sebagainya cenderung terabaikan.

Demikian pula dengan apresiasi terhadap pengawas sekolah. Pengawas sekolah masih termarjinalkan. Padahal kalau dilihat dari tugas pokok dan fungsi pengawas, peran pengawas sekolah sebagai penjamin mutu pendidikan di sekolah binaanya dinilai sangat stategis. Secara umum, Terdapat beberapa masalah terkait dengan pengawasan. Pertama tentang kinerja pengawas sekolah selama ini, baik dari sisi rendahnya kinerja, sikap, kompetensi, intensitas sampai pada tidak efektifnya sistem pengawasan. Kedua berkenaan dengan jumlah pengawas. Ditemukan beberapa masalah, di antaranya tidak proporsionalnya jumlah dibandingkan dengan sekolah, guru binaan, sebaran sekolah. Ketiga berhubungan dengan latar belakang pengawas terdapat permasalahan yang cukup kompleks, yaitu sebagian pengawas tidak berlatar belakang pendidikan keguruan (pendidikan).

\section{Kajian Literatur}

\section{A. Pengertian Pengawas Sekolah}

Secara etimologis, kata pengawasan (supervise) merupakan istilah yang dalam bahasa Inggrisnya supervision, terdiri dari dua kata, yaitu super dan vision, yang berarti melihat dengan teliti pekerjaan secara keseluruhan. Sedangkan orang yang melakukan kegiatan supevisi tersebut, dikenal dengan supervisor (pengawas). ${ }^{1}$

Jadi supervisi mempunyai pengertian luas, supervisi adalah segala bantuan dari para pemimpin sekolah dan supervisor, yang tertuju kepada perkembangan kepemimpinan guru-guru dan personil sekolah lainnya di dalam mencapai tujuan pendidikan. $^{2}$

\section{B. Ruang Lingkup dan Tugas Pokok Pengawas Sekolah}

Ruang lingkup Pengawas Sekolah berdasarkan PMA No. 2 Tahun 2012 tentang Pengawas Sekolah dan Pengawas Pendidikan Agama Islam pada Sekolah yang telah diubah oleh PMA No. 31 tahun 2013 tentang Perubahan Atas PMA No. 2 Tahun 2012 pasal 1 ayat 3 adalah melaksanakan supervisi menejerial dan supervisi akademik.

Tugas pokok Pengawas Sekolah adalah menyusun program pengawasan sekolah, melaksanakan pembinaan, melakukan pemantauan dan penilaian, menyusun laporan pelaksanaan program pengawasan, melaksanakan bimbingan dan pelatihan profesionalitas kepala sekolah dan tenaga kependidikan lainnya. 
Edu Riligia : Vol. 4 No. 1 Januari- Maret 2020

\section{Peran Pengawas Sekolah}

Pengawas sekolah memiliki peran yang strategis dalam proses pendidikan yang bermutu di sekolah. Dalam konteks ini peran pengawas sekolah meliputi pemantauan, supervisi, evaluasi, pelaporan, dan tindak lanjut pengawasan yang harus dilakukan secara berkesinambungan (PP Nomor 19 tahun 2005, Pasal 55).

Peran tersebut berkaitan dengan tugas pokok pengawas sekolah dalam melakukan supervisi akademik dan supervisi manajerial serta pembinaan, pemantauan, dan penilaian. Peran pengawas sekolah dalam pembinaan setidaknya sebagai teladan bagi tenaga pendidik di sekolah dan rekan kerja yang serasi dengan pihak sekolah dalam memajukan sekolah binaannya. Peran pengawasan tersebut dilaksanakan dengan pendekatan supervisi yang bersifat ilmiah, klinis, manusiawi, kolaboratif, artistik, interpretatif, dan berbasis kondisi sosial budaya.

\section{D.Fungsi dan Tugas Pengawas}

Fungsi pengawas dalam pendidikan bukan hanya sekedar kontrol melihat apakah segala kegiatan telah dilaksanakan sesuai dengan rencana atau program yang telah digariskan, tetapi lebih dari itu, supervisi dalam pendidikan mengandung pengertian yang luas. Kegiatan supervise mencakup penetuan kondisikondisi atau syarat-syarat personil maupun material yang diperlukan untuk terciptanya situasi belajar mengajar yang efektif dan usaha memenuhi syarat-syarat itu.

Jadi, tugas terpenting pengawas adalah memberikan berbagai alternatif pemecahan masalah dalam pembelajaran. Bila terjadi sesuatu yang timbul atau mencuat kepermukaan yang dapat mengganggu konsentrasi proses belajar mengajar, maka kehadiran pengawas bersifat fungsional untuk melakukan perbaikan. Oleh karena itu, pemberdayaan pengawas diperlukan untuk meningkatkan fungsinya sebagai motivator, fasilitator dan sekaligus katalisator pengajaran. ${ }^{3}$

\section{E. Tipe-tipe Kepengawasan}

Burton dan Brueckner dalam Purwanto menyatakan bahwa adanya lima tipe pengawasan yaitu: inspeksi; Laissez- Faire; coercive; training and guidance; dan democratic leadership. Kelima tipe tersebut adalah sebagai berikut: ${ }^{4}$

a) Tipe Inspeksi

Inspeksi dijalankan terutama dimaksud untuk meneliti/mengawasi apakah guru menjalankan apa-apa yang sudah diinstruksikan dan ditentukan oleh atasan atau tidak. 
Syamsu Nahar: Peran Kepala Sekolah dalam Meningkatkan Profesionalitas Guru

b) Tipe Laissez- Faire

Kepengawasan Laissez- Faire yaitu dengan membiarkan guru-guru bekerja sekehendaknya tanpa diberi petunjuk dan bimbingan.

c) Tipe Coercive

Tipe kepengawasan Coercive Supervision bersifat otoriter, yaitu di dalam tindakan kepengawasannya pengawas bersifat memaksakan segala sesuatu yang dianggapnya benar dan baik menurut pendapatnya sendiri

d) Tipe Training and Guidance

Tipe latihan bimbingan berlandaskan suatu pandangan bahwa pendidikan itu merupakan proses pertumbuhan bimbingan dan orang-orang yang diangkat sebagai guru pada umumnya telah mendapat pendidikan pre-service di sekolah guru

e) Tipe Democratic Leadership

Tipe demokratis ini, pengawas bukan lagi suatu pekerjaan yang dipegang oleh seorang petugas, melainkan merupakan pekerjaan bersama yang dikoordinasikan.

\section{F. Profesionalitas Guru}

Profesionalitas secara bahasa berasal dari bahasa Inggris "profession", bahasa latin "profesus", yang berarti mampu atau ahli dalam suatu bentuk pekerjaan. ${ }^{5}$ Jadi profesionalitas merupakan seorang yang ahli pada bidang tertentu yang ditekuni serta terdidik melakukan profesi tersebut.

Guru yang profesional adalah orang yang terdidik dan terlatih dengan baik serta memiliki pengalaman yang kaya dibidangnya, ${ }^{6}$ mendukung statemen tersebut, Oemar Hamalik juga menjelaskan bahwa guru profesionalitas adalah orang yang telah menempuh program pendidikan guru dan memiliki tingkat master serta telah mendapat ijazah negara dan telah berpengalaman mengajar pada kelas-kelas besar. ${ }^{7}$

\section{Metode Penelitian}

Penelitian ini menggunakan pendekatan kualitatif deskriptif. Pendekatan ini bermaksud memberikan gambaran atau deskripsi suatu peristiwa secara sistematik dan objektif dengan cara mengumpulkan, mengevaluasi, memverifikasi, serta mensintesiskan bukti-bukti untuk mendukung fakta guna memperoleh suatu kesimpulan. 
Edu Riligia : Vol. 4 No. 1 Januari- Maret 2020

Penelitian deskriptif kualitatif merupakan metode penelitian yang mendalam tentang realitas sosial dan berbagai fenomena yang terjadi di masyarakat yang menjadi subjek penelitian sehingga tergambarkan ciri, karakter, sifat, dan model dari fenomena tersebut. ${ }^{8}$

\section{Hasil dan Pembahasan}

A. Perencanaan kepala sekolah dalam mengembangkan profesionalitas guru di SMP Negeri 1 Halongonan Timur Kabupaten Padang Lawas Utara.

Berdasarkan dari data yang peneliti dapatkan, maka peneliti dapat menyimpulkan bahwa untuk mengembangkan profesionalitas guru memang sangat perlu adanya perencanaan yang matang, dan perencanaan yang telah di buat oleh kepala sekolah SMP Negeri 1 Halongonan Timur Kabupaten Padang Lawas Utara sudah terbilang sangat baik. Untuk mencapai tujuan pendidikan serta visi dan misi sekolah unsur yang paling penting adalah seorang guru, guru memang peranan penting di sekolah maka yang pertama sekali yang perlu di kembangkan adalah professional gurunya.

B. Pelaksanaan supervisi kepala sekolah dalam mengembangkan profesionalitas guru di SMP Negeri 1Halongonan Timur Kabupaten Padang Lawas Utara

Berdasarkan pengamatan peneliti dilapangan pada saat selesai kegiatan upacara bendera kepala sekolah mulai berkeliling kelas walaupun hanya sekedar menyapa siswanya dan guru yang sedang mengajar dikelas. Kepala sekolah memang tidak menetukan hari apa dan jam berapa beliau akan mengawasi untuk memperhatikan para guru, namun beliau selalu menyempatkan dalam seminggu sekali untuk berkeliling kelas karena beliau menyadari bahwa menjadi seorang kepala sekolah itu harus perduli terhadap gurunya sehingga para guru merasa nyaman dan ketika disupervisi tidak segan untuk bertanya akan kendala dan masalah yang dihadapi guru tersebut.

C. Tindakan kepala sekolah dalam memotivasi guru di SMP Negeri 1 Halongonan Timur Kabupaten Padang Lawas Utara

Keberhasilan Motivasi ekstrinsik yang dilakukan Kepala sekolah di SMP Negeri 1 Halongonan Timur Kabupaten Padang Lawas Utara dalam memotivasi gurunya beliau selalu memberikan pujian, beliau menyadari bahwa seseorang sangat senang dipuji, dihargai, didengar dan diakui. Beliau juga selalu 
Syamsu Nahar: Peran Kepala Sekolah dalam Meningkatkan Profesionalitas Guru

menghargai setiap pendapat guru pada saat rapat. Motivasi juga dilakukan dengan memberikan pelatihan-pelatihan yang dapat membagun wawasan guru juga dapat membagun karakter guru menjadi lebih baik. Dan motivasi yang ada pada diri guru sendiri yaitu guru tersebut ingin meningkatkan jenjang karirnya di sekolah itu, pada saat pelatihan beliau tidak dapat hadir karena sakit dan akhirnya beliau belajar dengan rekannya kerja yang mengikuti pelatihan itu, dengan begitu guru tersebut tetap mendapatkan ilmunya.

\section{Kesimpulan}

Berdasarkan penelitian di lapangan didapatkan beberapa temuan bahwa: Perencanaan kepala sekolah dalam mengembangkan profesionalitas guru di SMP Negeri 1 Halongonan Timur Kabupaten Padang Lawas Utara yaitu mulai dari perencanaan merekrut guru baru, dalam merekrut guru baru kepala sekolah menentukan atau membuat kreteria, dan bagi calon guru yang memiliki kreteria tersebutyang bisa bekerja di sekolah itu, kreteria tersebut misalnya pendidikan minimal S1 dan hafal surah-surah pendek. Dan juga diadakanya pelatihan di bidang IT karna kepala sekolah sadar bahwa 80\% gurunya masih belum menguasai IT, hal tersebut juga direncanakan untuk mengembangkan kurikulum KTSP menjadi K13. Perencanaan juga di lakukan dengan menghemat dana sekolah yaitu kepala sekolah dan wakil kepala sekolah yang mengerjakan pekerjaan administrasi, tidak ada tenaga administrasi khusus.

Pengawasan kepala sekolah dalam mengembangkan profesionalitas guru di SMP Negeri 1 Halongonan Timur Kabupaten Padang Lawas Utara adalah dengan pengawasan secara berkala yaitu seminggu sekali. Pengawasannya dilakukan dengan model pengawsan formatif dan sumatif yaitu Kepala sekolah langsung masuk ke dalam kelas memperhatikan cara guru mengajar dan itu dilakukan secara berkesinambungan. kepala sekolah pun sering memberi saran atau masukan setelah guru itu selesai mengajar, serta kebebasan kepada guru untuk menerapkan motede-metode pengajaran yang baru agar siswa lebih semangat belajar.

Motivasi yang diberikan kepala sekolah dalam mengembangkan profesionalitas guru di SMP Negeri 1 Halongonan Timur Kabupaten Padang Lawas Utara atau yang disebut motivasi eksterinsik adalah dengan memberikan pujian kepada guru atas kinerjanya. Dan selalu bersikap menghormati guru, mendengarkan keluhan guru dan menindaklanjuti apa yang menjadi keluhan guru 
Edu Riligia : Vol. 4 No. 1 Januari- Maret 2020

serta memberikan pelatihan pengembangan bagi guru yang tertinggal di bidang IT. Sedangkan motivasi yang memang ada pada diri guru sendiri atau yang disebut motivasi interinsik yaitu pada saat ada pelatihan guru tidak dapat hadir mengikuti pelatihan tersebut tetapi karena guru tersebut ingin memperoleh ilmu tersebut maka guru itu belajar kepada rekannya agar guru tersebut dapat terus meningkatkan kemampunya.

\section{Endnote:}

${ }^{1}$ Departemen Agama RI, Kepengawasan Pendidikan (Jakarta: Dirjen Kelembagaan Agama Islam, 2005), h. 2.

2 Ngalim Purwanto, Administrasi dan Supervisi Pendidikan, Cet. 19, (Bandung: PT. Remaja Rosdakarya, 2009), h. 76.

${ }^{3}$ Amiruddin Siahaan Manajemen Pengawas Pendidikan,(Ciputat: Quantum Teaching, 2006), h. 2 .

${ }^{4}$ Nana Sudjana, Standar Mutu Pengawas, (Jakarta: Depdiknas, 2006), h. 73.

5 Ahmad Sanusi, Studi Pengembangan Model Pendidikan Profesional Tenaga Kependidikan, (Bandung: IKIP, 1991), h.18.

${ }^{6}$ Kunandar, Guru Profesional, Implementasi Kurikulum Tingkat Satuan Pendidikan (KTSP) dan Persiapan Menghadapi Sertifikasi Guru. (Jakarta: Raja Grafindo Persada, 2007), h. 46-47.

7 Oemar Hamalik, Pendidikan Guru Berdasarkan Pendekatan Kompetensi, cet. ke-4, (Jakarta: PT. Bumi Aksara, 2006), h. 27.

8 Wina Sanjaya, Penelitian Pendidikan: Jenis, Metode dan Prosedur, Jakarta: Prenada Media Group, 2013), h. 47. 
Edu Riligia : Vol. 4 No. 1 Januari- Maret 2020

\section{DAFTAR PUSTAKA}

Amiruddin. Administrasi Pendidikan. Bandung: Cipta Pustaka. 2011.

Departemen Agama RI. Kepengawasan Pendidikan. Jakarta: Dirjen Kelembagaan Agama Islam. 2005.

Hamalik, Oemar. Pendidikan Guru Berdasarkan Pendekatan Kompetensi. Cet. IV. Jakarta: PT. Bumi Aksara. 2006.

Kunandar. Guru Profesional, Implementasi Kurikulum Tingkat Satuan Pendidikan (KTSP) dan Persiapan Menghadapi Sertifikasi Guru. Jakarta: Raja Grafindo Persada. 2007.

Purwanto, Ngalim. Administrasi dan Supervisi Pendidikan. Cet. XIX. Bandung: PT. Remaja Rosdakarya. 2009.

Sanjaya, Wina. Penelitian Pendidikan: Jenis, Metode dan Prosedur. Jakarta: Prenada Media Group. 2013.

Sanusi, Ahmad. Studi Pengembangan Model Pendidikan Profesional Tenaga Kependidikan. Bandung: IKIP. 1991.

Siahaan, Amiruddin. Manajemen Pengawas Pendidikan. Ciputat: Quantum Teaching. 2006.

Sudjana, Nana. Standar Mutu Pengawas. Jakarta: Depdiknas. 2006. 